\title{
What Impact of Social Networks on Farmers' Performances; Case of The Milk Sector in Ghardaïa, Algeria
}

\author{
Manal NECHAR ${ }^{*}$, Sami ASSASSI ${ }^{2}$, Mohammed BENDRISSOU ${ }^{3}$
}

\begin{abstract}
In many developing countries, farmers are struggling to improve their productivity and economic performance. This is due to the markets' imperfections, including information market. Numerous empirical studies point to the limitations of the so-called conventional information system set up by public institutions, which forces farmers to bear significant additional transaction costs to access information. These limits have led to the emergence of other modes of information transfer, of which collaboration seems to be the most successful. Social networks, by their very conception, have allowed this mode to materialise and develop rapidly. Algeria is no exception, since these techniques are found in some of the country's agricultural contexts. By analyzing the dairy value chain in the wilaya of Ghardaïa (South of the country), we evaluate in this study the impact of the use of social networks on farmers' performance. We surveyed 50 farmers in the region, randomly selected using the snowball method - one respondent leads to another. The results highlight the relevance of information obtained from social networks, which allows farmers to make savings (13.000 DZD per year per dairy cow: production and transaction costs) and technical changes, and thus leads to a significant improvement in productivity and economic performance (net profit per year per dairy cow: 170.000 DZD versus 78.000 DZD, net profit per litre of milk: 20 DZD versus 11 DZD respectively). The study shows, however, that the use of social networks is not generalized and remains subject to structural variables specific to farmers such as age and level of education.
\end{abstract}

Keywords: Innovation, Information system, Social networks, Impact, Performances, Dairy farmers, Algeria.

\footnotetext{
1*Sorumlu Yazar/Corresponding Author: Dr. Manal NECHAR, National Higher School of Agronomy (ENSA), Rural Economy Department, Algiers, Algeria. E-mail: nechar_manal@hotmail.com OrcID: 0000-0002-3890-4801

${ }^{2}$ Dr. Sami ASSASSI, , National Higher School of Agronomy (ENSA), Rural Economy Department, Algiers, Algeria. E-mail: assassisami@hotmail.com (iD) OrcID: 0000-0002-1325-0207.

2 Mohammed BENDRISSOU, National Higher School of Agronomy (ENSA), Rural Economy Department, Algiers, Algeria. E-mail: mohammed.bendrissou@gmail.com (iD) OrcID: 0000-0002-8936-5502.

Atıf/Citation: NECHAR M., ASSASSI, S., BENDRISSOU M. What Impactof Social Networks on Farmer's Performances: Case of The Milk Sector in Ghardaïa, Algeria, Tekirdă̆ Ziraat Fakültesi Dergisi, 18 (4), 625-635.

CBu çalışma Tekirdağ Namık Kemal Üniversitesi tarafından Creative Commons Lisansı (https://creativecommons.org/licenses/by-nc/4.0/) kapsamında yayınlanmıştır. Tekirdağ 2021
} 


\section{Introduction}

Conventional information systems are often presented by analysts as one of the main causes of entrepreneurial failure (Ramezani et al., 2021). In order to compensate for the inadequacies of conventional systems, several mechanisms, developed by private initiatives, are gradually being imposed on the market. For a better understanding, in economics, these mechanisms are read through the theory of induced institutional change of Ruttan and Hayami (1984).

These authors consider that institutional changes are endogenous, if they result mainly from technical changes that lead to a modification of the relative prices of factors. Basically, two types of information transfer mechanisms can be distinguished. The first consists of vertical mechanisms, generated by private actors, suppliers and customers (seed companies, importers - Goulet, 2011; Laouar and Dugué, 2019). These appear in particular in the context of coordination practices, for example contract farming, where private companies, which have directly invested in improving crop yields, provide technical advice to farmers (Assassi et al., 2020). These mechanisms are also observed in agricultural markets, where information about technology and market demand is channelled through traders (Assassi et al., 2017). The second category is collaborative, horizontal mechanisms: exchanges between farmers themselves (Isollah et al., 2010; Hansen et al., 2014; Casey et al., 2016).

Collaborative mechanisms have developed significantly around the world, especially social networks (SNs), thanks to the widespread use of the internet. In this text, SNs refer to the digital exchange platforms of the web (such as Facebook and YouTube, etc.). SNs technologies have been around since the 1990s, but it is especially since the 2000s that their use and usage has increased significantly, with the use of mobile phones (Casey et al., 2016).

Several researchers have analysed the effectiveness of collaborative systems via SNs and show that they allow farmers to access relevant information on production techniques, innovation and markets quickly and cheaply, helping them to improve their productivity and economic performance (Galtier et al., 2014; Allen et al., 2012; Wyn and Penri, 2017; Bite and Anand, 2017). Others have attempted to identify the strengths and weaknesses of the conventional information system and make proposals to improve its performance (Demiryurek, 2008; Vidanapthirana, 2012; Kizilaslan, 2006) but whose results encourage the adoption of collaborative system.

These mechanisms are increasingly observed in developing countries (Mukherjee et al, 2017). Algeria is no exception, with this collaborative system gaining ground in some sectors and regions (Issolah et al, 2010; Laouar and Dugué, 2019). But in this context, these mechanisms are rarely discussed. This article attempts, therefore, to conduct a pioneering analysis of these emerging collaborative mechanisms via SNs within the strategic milk sector in Ghardaïa, a region that has experienced great agricultural development in recent years (Ministry of Agriculture and Rural Development - MADR, 1998 and 2015). Our main research question is the following: what is the impact of the use of the SNs on the breeders' performance. It is thus a question to know (i) whether the place that SNs occupy in the sector studied, (ii) the determinants of their use and (iii) to what extent they are able to fill the gap left by the conventional information system.

The remainder of the text is organized as follows: The first part describes the study region and provides a review of the literature on the 'standard', or 'conventional', information system in Algeria, its shortcomings, the information needs expressed by farmers and the new information modes that are emerging, including SNs, and then describes the survey conducted among farmers. The second part is devoted to the presentation of the survey results, and the third part is dedicated to the discussion of the obtained results.

\section{Context, methodology and surveys}

\subsection{Study Region}

The study region, the wilaya (county) of Ghardaiia, is in a vast arid zone of the Algerian Sahara, $600 \mathrm{~km}$ south of Algiers (Figure 1). Ghardaïa has a surface area of 8.4 million ha, including a utilized agricultural area of 44 ha 
(MADR, DSA $\left.{ }^{1}, 2017\right)$. It is characterized by a hyper-arid Saharan climate, which results in high average annual temperatures, sometimes above $45^{\circ}$.

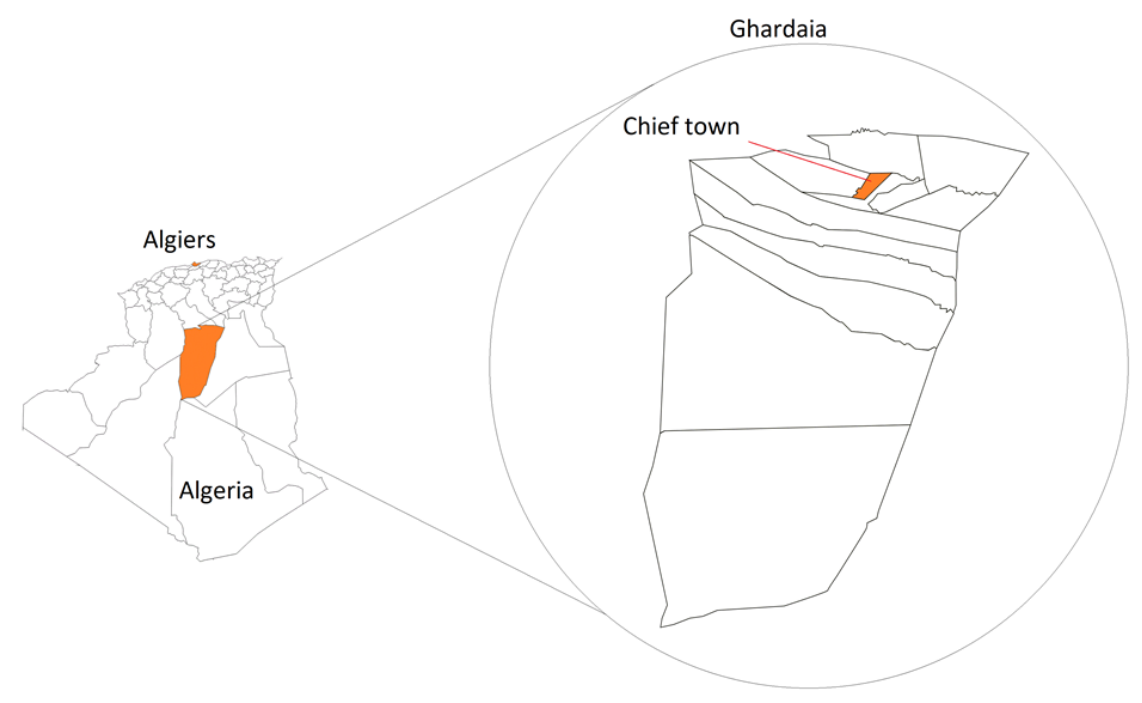

Developed by ourselves using maps from d-maps.com.

Figure 1. Location of the study area

The region's agriculture, formerly dominated by date palms (1.1 million productive palm trees, MADR, DSA 2017), has been gradually transformed and diversified following the implementation of various development policies during the 1980s, notably the law on Accession to Agricultural Land Ownership (APFA - Baroud et al., 2018). New agricultural dynamics based on the exploitation of new sites, underground water and the introduction of new crops with high added value (cereals, market gardening, arboriculture, livestock farming) have been emerging in the region for several decades. In December 2017, Ghardaïa totaled 75 major agricultural investments covering an area of 15.000 ha.

Dairy cattle breeding is one of the new dynamics which is undergoing significant development in Ghardaïa. The volume of milk collected exceeded 13 million liters in 2017 (making it the leader in its region, i.e. 74\% of the production of the great Algerian south ${ }^{2}$ - DSA, 2017) to reach 15 million liters during the 2018-2019 campaign. In 2016, Ghardaïa had 2.700 dairy cows spread over 170 dairy farms (according to the DSA).

In Ghardaïa, most herders do not own land (landless livestock farming), which forces them to outsource their cattle feed to other farmers and feed mills. To this dependence is added the absence of a physical market to match supply and demand, so these herders are left to find on their own, the right supplier, check and compare prices and quality.

Concerning dairy cows, the livestock of the wilaya is exclusively made up of modern dairy cattle of imported breeds. Herders in Ghardaïa are also expanding their herd through the purchase of heifers from other local herders. That said, the breeders still express a need for support given their lack of experience working with this breed of cattle in the region and the scarcity of information surrounding it.

As for marketing, it is done entirely through triangular marketing contracts specifying prices and quantities, signed between farmers, private collectors and the 11 dairies present in the wilaya. These contracts are part of a broad national coordination mechanism, contract faring, set up by the state in 2009. The state provides premiums for farmers, collectors and dairies (14.5 and 10 DZD per liter of milk produced, collected and processed respectively, in this framework) in order to encourage them to adhere to these contracts (Daoudi et al., 2017). The dairies have a total processing capacity of 75.500 liters per day (MADR, DSA, 2020), giving them the capacity to absorb the region's production without any difficulty and thus avoid any disposal problems for farmers. In

\footnotetext{
${ }^{1}$ Directorate of Agricultural Services

${ }^{2}$ The wilayas of the great south of Algeria are Ghardaia, Ouargla, El Oued, El Bayedh, Laghouat, Djelfa, Naama, Bechar, Tindouf, Adrar, Tamenrasset and Illizi.
} 
Nechar \& Assassı \& Bendrissou

What Impact of Social Networks on Farmer's Performances: Case of The Milk Sector in Ghardaïa, Algeria Ghardaïa, farmers sell milk at a price between 62 and 64 DZD per liter. From this total price, the dairies are paying farmers 48 to 50 DZD and the rest of 14 DZD is paid by the state (12 DZD plus 2 DZD if the farmer has a health approval) plus $0.5 \mathrm{DZD}$ for each additional gram of fat contained in the milk over the threshold of $34 \mathrm{~g}$ per liter (Decision No. 528 of 08 May 2016, MADR).

\subsection{Conventional agricultural information system: between stakeholders' expectations and the limits of supply}

In Algeria, the content of the information campaigns is developed by the technical institutes (National Institute of Agricultural Extension, Technical Institute of Marshland and Industrial Crops, Technical Institute of Livestock, Technical Institute of Field Crops). The difficulties that these institutes face when transmitting information to the farmers are often observed (Bedrani, 1993, Anseur, 2009; Issolah et al., 2010). This is due to the divergence, both spatial and functional, between these institutes and farmers. Algerian farms, especially those that have emerged in the new agricultural basins, such as Ghardaïa, are widely dispersed in space and are often very far from urban centers, and therefore from state institutions. Lacking the necessary means (transport means, manpower, etc.), state institutions could not manage to ensure proximity support to the farmers. The national average being less than one extension worker per commune (all sectors). This manpower lack does not allow proximity extension, forcing farmers to travel to these institutions to obtain the needed information. Beside the significant internal material difficulties (equipment, laboratories, financing) faced by Algerian technical institutes, the geographical distance between farmers and extension workers also hinders the transfer of information on farmers' needs (Bedrani, 1993; Issolah et al., 2010). This remoteness is increased crucially by the development of agriculture in the Saharan and steppe regions (Bedrani, 1993; Bedrani 1994; Anseur, 2009; Issolah et al., 2010; Assassi et al., 2017).

These findings are validated by dairy cattle breeders in the Bouira, Algiers and Boumerdes regions surveyed by Anseur (2009), who affirm the existence of this gap between the need of information and its supply. These breeders, expressed in particular, the need of precise and urgent information concerning the choice of breeds, animal health, food and reproduction. They qualified the information offer of these institutes as insufficient, out of step and difficult to access (Jargon, dissemination platform, distance from the premises of institutes, absence of delegates, etc.). So, they are therefore forced to incur significant transaction costs, particularly in terms of research, to fill this void. The wilaya of Ghardaïa, by being in the Saharan region, the problem is even greater, in fact the wilaya has 15 extension workers for 16.129 farmers (MADR, DSA, 2018) all sectors combined. It would be worth mentioning that this workforce does not have a vehicle and has not benefited from training dedicated to the mastery of extension approaches nor communication skills. These circumstances have contributed to strengthening exchanges between farmers themselves, particularly via information and communication technologies, to the detriment of those with institutes' experts (Issolah et al., 2010).

\subsection{Methodology, data and surveys}

This study aims to assess the relevance of SNs as a new mode of access to information by determining the impact of social networks on farmers' economic performance. We first evaluated the use, or not, of SNs. We then studied the determinants of their use. Finally, we evaluated their impact on farmers' performance. For the impact study, we compared the benefits of two groups of farmers, those who use SNs and those who do not. The differences observed were used to identify the factors determining the use of SNs. We then compared these determinants according to different factors, namely the cost structure (feed price, personnel costs, veterinary costs, transport costs, electricity costs) and the determinants of milk yields (quantity and quality of feed, veterinary care and labour). Finally, we highlighted the links between the use of SNs and the differences in input costs, quality and quantity between the two groups studied.

To carry out this methodology, we used analytical methods and some statistical tools:

- The student's t-test is used to characterise the two groups of farmers, and to identify the main differences between them that could explain the use of SNs. The same test was used again to compare performance indicators and technical itineraries (feed, labour, veterinary care) between the two groups of farmers.

- The OLS regression allowed the identification of the production factors that are the most important determinants of the variation in performance.

- Pearson's KHI 2 and Cramer's V tests were used to assess the influence of factors in order to validate results obtained by reading the determinants of $\mathrm{SN}$ use. 
- A descriptive study and a qualitative reading were used to highlight the information domains sought by farmers and compare them with the types of information found on the SNs.

This approach also allowed us to attribute the differences between the two groups of farmers to the use or nonuse of SNs. The implementation of this methodology required several pieces of information from farmers (SNs users, and non-users), namely: their structural characteristics (age, education, etc.), farm functioning, performance (costs, returns and net benefits, etc.) and use of SNs. This information was collected through a face-to-face survey of dairy farmers, users and non-users of SNs during April and May 2019. In the face of the inexistence of an exhaustive list of producers in the region, the study sample was constituted using the snowball method - one respondent leads to another. The only selection criterion was to be a dairy farmer in the wilaya. A sample of 50 users and non-users of SNs was constituted (30\% of farmers in the region. in our judgment).

The survey questionnaire is organised in three parts, each with a specific objective. Data from the exploratory surveys, as well as numerous bibliographic works on SNs, were used to construct the content of the three parts (Anseur, 2009; Wyn and Penri, 2017; Bite and Anand, 2017), devoted respectively to the characterisation of the farmers and their farms, the sources of information they use and their performance.

\section{Results and Discussion}

\subsection{Characterization of livestock keepers and analysis of the determinants of the use of social networks}

Our sample consisted of two groups: the first is the SNs users, with 31 farmers. The second is the SNs nonusers, and it includes 19 farmers. The sample characteristics are presented in Table 1. The comparison presented in the Table is based on Student's test. It reveals more differences than similarities. Some differences are significant at the $5 \%$ confidence level such as age, internet use, education level and performances.

The others are not significant at the $5 \%$ confidence: the practice of plural-activity, forage area, number of cows, number of employees, investment. When compared to non-users, 3 criteria emerge where the differences are crucial: age (the SNs users are younger), the degree of internet «dependency » (the users use the internet more frequently) and the education (the users are more educated). Some of these differences (see Table 1), for example: investment, farm size - number of cows and employees - intermediate consumption, when considered with some field observations such as: profiles, risk-taking, objectives, show that the SNs users includes relatively more entrepreneurial farmers.

Table 1. Characterization of livestock owners as users and non-users of social networks

\begin{tabular}{|c|c|c|c|c|c|}
\hline & \multicolumn{2}{|c|}{$\begin{array}{c}\text { Non-users of social networks } \\
\mathrm{N}=19(38 \%) \\
\end{array}$} & \multicolumn{2}{|c|}{$\begin{array}{c}\text { users of social networks } \\
\mathrm{N}=31(62 \%) \\
\end{array}$} & \multirow[b]{2}{*}{ t-value } \\
\hline & Mean & Standard deviation & Mean & Standard deviation & \\
\hline \multicolumn{6}{|l|}{ Breeder } \\
\hline Age (years) & 52 & 5.50 & 37 & 8.08 & $6.88^{* * *}$ \\
\hline Internet use (\%) & 0 & 0.00 & 100 & 0.00 & $1.00 * * *$ \\
\hline Educational level (years) & 6 & 2.23 & 11 & 1.99 & $-5.50 * * *$ \\
\hline Practice of multiple activities (\%) & 0 & 0.00 & 0.09 & 0.30 & -1.39 \\
\hline \multicolumn{6}{|l|}{ Holding } \\
\hline Surface area used (ha) & 2.58 & 1.88 & 14.11 & 62.35 & -0.80 \\
\hline Number of cow & 21 & 16.69 & 40 & 55.63 & -1.44 \\
\hline Number of employees & 2 & 1.50 & 3 & 4.38 & -1.15 \\
\hline Investment (DZD) & $2.735,789$ & $1.481,010$ & $5.157,096$ & $7.999,910$ & -1.30 \\
\hline \multicolumn{6}{|l|}{ Productive performance } \\
\hline Total production (l) & 148.736 & 125.515 & 326.835 & 434.902 & $-1.73^{*}$ \\
\hline Yield per cow (1) & 6.915 & 418 & 8.216 & 664 & $-7.63 * *$ \\
\hline
\end{tabular}

* Significant at the $10 \%$ level; ** Significant at the $5 \%$ level; *** Significant at the $1 \%$ level. 
Furthermore, these results suggest that the use of SNs could be conditioned by certain structural criteria. According to the "technology acceptance model" proposed by Davis in 1989 (Davis et al., 1989), the adoption of technology is conditioned by the perceived usefulness and its ease of use. So the use of SNs in the case study is determined firstly by farmers' needs, and secondly by their ability to access the information available on this platform. Fieldwork shows that approximatively $68 \%$ of non-SNs farmers do not use these SNs because their lack of familiarity with the new technologies. More than $32 \%$ of them show little interest in SNs. In order to obtain information, they mainly turn to professional agricultural organizations that they consider satisfactory. They also exchange information between farmers but in the conventional ways: phone calls and SMS. Nevertheless, it should be stressed that they adopt a collaborative attitude by referring to farmer-to-farmer exchange as a means of information, as indicated in previous work (Issolah et al., 2010).

In addition, livestock farmers using SNs utilize this technology to learn about their field of activity. because of their dissatisfaction with the standard information system (93\%), which is considered poorly accessible and moderately relevant. SNs are also in this case as a mean of communication and exchange with other farmers, again for information purposes.

As can be seen from the characterization of the two groups of livestock owners surveyed (Table 1), the lack of mastery of SNs can in turn be explained mainly by two factors, namely age and level of education. The use of such platforms requires a minimum level of computer and language skills (Arabic and French in particular). Non-users of SNs are relatively old ( 15 years older than the users) and poorly educated (5 years less education) and are more likely to encounter difficulties in accessing SNs themselves. The results of Pearson and Carmer's tests, shown in Table 2, demonstrate the existence and importance of relationships between the determinants (education and satisfaction with the standard system) and the use of SNs and thus validate these results.

Table 2. Measuring the influence of factors on the use of social networks

\begin{tabular}{lcccc}
\hline & Pearson Chi-Square & Asymp.Sig & Cramer's V & Approx.Sig \\
\hline Age & $26.55^{*}$ & 0.00 & $0.72^{* * *}$ & 0.00 \\
Educational level & $31.75^{*}$ & 0.00 & $0.79^{* * *}$ & 0.00 \\
Satisfaction with the standard system & $45.89^{*}$ & 0.00 & $0.95^{* * *}$ & 0.00 \\
\hline
\end{tabular}

$\mathrm{P}<1 \% * ; \mathrm{V}>0.7 * * *$

\subsection{Characterization of social networks}

Overall, the survey highlights three main domains of information sought by livestock farmers, namely innovations (100\%), input supply (90\%) and animal health (64\%). The use of SNs enables livestock owners, most of them are located far from urban centers, to keep abreast of technical progress. Regarding supply, livestock owners aim to have access to inputs that are cheaper and have a better quality. The inputs concerned are essentially related to livestock feed, particularly green fodder and concentrated feed. At this level, livestock owners are trying to widen their circle of input providers by broadening their networks via SNs in order to maximize choices whenever a supply operation is planned. Another priority in which SNs are used is to look after recruitment, by searching for skilled labour. In terms of health, livestock farmers seek information on preventive monitoring and damage control, in order to react quickly in the event of health problems or digestive pathologies, which are very detrimental to production, or even the life of the animal.

The respondents also state that the information available on SNs mainly concerns the latest breeding techniques adopted and the latest technological inventions (96\%). By using SNs, livestock farmers say they have access to a more abundant supply at competitive prices (70\%), particularly in terms of animal feed, spare parts and second-hand equipment, and even acquire "soft" veterinary knowledge (93\%) enabling them to diagnose certain pathologies (lameness and digestive disorders) and react quickly. Even labour recruitment (45\%) seems to be much more attractive in the SNs than in the conventional labour market, both in terms of the number and nature of qualifications offered and the wages demanded.

Among the wide range of SNs available on the web, Facebook and YouTube seem to be the favored by our sample of breeders. YouTube is appreciated for its illustrative videos, while on Facebook there are different platforms: pages, groups, people and marketplace. The totality of farmers who are using SNs adhere to groups on Facebook, of which 
the best known are (i) "agriculture in Algeria", used by 52\% of respondents and totaling more than 19.000 members with an average of 60 publications per day, (ii) and "milk producers in Algeria", used by $48 \%$ of respondents and with 20.000 members making an average of 50 publications per day.

In order to understand this new behaviour, it is necessary to take a closer look at the mechanisms underlying the functioning of SNs; the creation of content, knowledge sharing and exchange (Casey et al., 2016), and above all, the free provision of services and the possibility of reaching a maximum audience.

The two Facebook groups we are interested in are specialized groups with an agricultural or dairy production theme. It should be remembered that these are public groups where all members can express an offer or a request free of charge. In addition to the groups, farmers also consult the specialized pages (92\%) for information related to their activity. The specialized pages differ from the groups in that members are not free to publish, but they can freely access, comment and share information published by the page moderators, usually experienced farmers.

On SNs, information has a viral effect. Because it is free, it spreads rapidly to reach a maximum audience in record time. This lightens the information quest for the breeder and saves him precious time and money.

Unlike farmers and herders in many countries, who have access during their working day (Casey et al., 2016), the surveyed farmers have to adapt to unpleasant experience of the unavailability of the internet network at site (in the farm) where the information is mostly needed, forcing them to delay the search until they go back home (generally after $8 \mathrm{pm}$ ). Resulting in a reduction of the responsiveness of herders to the problems they may encounter during the day while working.

\subsection{Effects of social networks on livestock performances}

On average, SNs-using farmers make a much higher net profit per cow than non-SNs users; 170.000 DZD compared to 78.000 DZD. The same is true for the net profit per liter of milk - respectively 20 DZD versus 11 DZD. It should be recalled that the selling price is the same for all farmers, i.e. 62 DZD per liter. This price is set by the state within the framework of contract farming and is practiced by all actors in Ghardaïa. Overall, variations in profit are explained by both production costs and yields per cow. The correlation coefficient between variations in costs and variations in profits per cow is $-66 \%$. The correlation coefficient between changes in yields and profits per cow is $92 \%$. In order to assess the effect of SNs on profits, we first need to determine the nature of their influence on these two determinants, costs and yields.

A comparison of the production costs per cow of users and non-users of SNs using the student test shows a slight difference. This difference is significant at the 5\% confidence level. These annual costs are 339.000 DZD per cow for SNs users and 351.000 DZD per cow for non-users. Respondents point to a positive effect of SNs on the prices of certain inputs. A comparison of the structure of these costs, including feed and electricity, which is considered one of the main expenses in dairy cattle farming (Delice et al., 2021), presented in Table 3, reveals significant differences. These concern green fodder costs at the $1 \%$ level and concentrate feed costs and personnel costs at the $5 \%$ level.

\section{Table 3. Comparison of cost structure per dairy cow between the two groups of farmers}

\begin{tabular}{lccccc} 
& \multicolumn{2}{c}{ Non-users social networks } & \multicolumn{2}{c}{ Users social networks } \\
& Mean & $\begin{array}{c}\text { Standard } \\
\text { deviation }\end{array}$ & Mean & $\begin{array}{c}\text { Standard } \\
\text { deviation }\end{array}$ & t-value \\
\hline Green fodder (DZD) & 114.000 & 10.000 & 114.000 & 7.000 & $-0.03^{* * *}$ \\
Concentrated feed (DZD) & 171.000 & 14.000 & 175.000 & 11.000 & $-0.97^{* *}$ \\
Veterinary care (DZD) & 4.000 & 946 & 3.000 & 930 & 1.14 \\
Staff costs (DZD) & 48.000 & 26.000 & 35.000 & 15.000 & $2.17^{* *}$ \\
Transport load (DZD) & 6.000 & 2.000 & 4.000 & 3.000 & 1.42 \\
Electricity charge (DZD) & 5.000 & 2.000 & 4.000 & 2.000 & 0.79 \\
\hline
\end{tabular}

* Significant at the $10 \%$ level; ** Significant at the $5 \%$ level; *** Significant at the $1 \%$ level.

Differences in feed costs are small. On the other hand, the difference noted for staff costs is significant and amounts to $37 \%$. On average, farmers using SNs manage to save 13.000 DZD per cow a year - what kind of relationship with SNs? 
Livestock farmers who are using the SNs assert their preference for recruitment via digital web platforms. They note that this is the main method of recruitment, especially for seasonal employees. They explain these preferences by the more abundant and interesting offer in terms of qualifications and salary. Indeed, seasonal employees interested in short-term recruitment (students, pupils, holidaymakers) offer their services on the SNs to quickly access jobs. The latter are generally less demanding in terms of salary. Beside the effect of SNs on labour costs, by making it easier for livestock keepers to find work, SNs also reduce transaction costs (recruitment, search for inputs).

As shown in Table 1, a significant difference of 5\% is also noted between the yields per cow of SNs users and non-users, which are the most important determinant of income. To nuance the relationship between SNs and yields, we first tried to detect the most important determinants of yields and then compare the combinations of inputs of SNs users and non-users. The results of the OLS regression, which attempts to explain the variations in yields by those of the production factors considered to be determining factors, by the experts (technicians and farmers), presented in Table 4, show a significant positive effect of concentrated feed, working time and veterinary care. This means that a variation in these elements induces a significant variation in milk yields.

Table 4. Determinants of milk yield per cow

\begin{tabular}{lcccc}
\hline \multirow{2}{*}{ Model } & \multicolumn{2}{c}{ Non-standardised coefficients } & $\begin{array}{c}\text { Standardised } \\
\text { Coefficients }\end{array}$ & t-value \\
\cline { 2 - 5 } & B & Standard error & $2,722.79$ & $1.81^{*}$ \\
(Constant) & $4,931.17$ & 0.18 & 0.02 & 0.20 \\
Green fodder (kg per year) & 0.04 & 0.38 & 0.33 & $2.45^{* * *}$ \\
Concentrated feed (kg per year) & 0.94 & 177.01 & -0.26 & $2.04^{* *}$ \\
Veterinary care (number of visits per year) & -361.88 & 0.59 & -0.33 & $2.60^{* * *}$ \\
Working hours (h) & -1.54 & &
\end{tabular}

* Significant at the $10 \%$ level; ** Significant at the $5 \%$ level; *** Significant at the $1 \%$ level.

The quantities (and/or qualities) of the most important inputs determining yields (concentrated feed, care and labour), used by SNs users and non-users, are compared. The result (Table 5) shows that only the difference in the consumption of concentrated feed, which is the most important determinant of yields, is significant at the $5 \%$ confidence level - what kind of relationship with SNs?

Table 5. Comparison of production factors per dairy cow between the two groups of farmers

\begin{tabular}{|c|c|c|c|c|c|}
\hline & \multirow{2}{*}{\multicolumn{2}{|c|}{$\begin{array}{c}\text { Non-users social networks } \\
\mathrm{N}=19(38 \%)\end{array}$}} & \multirow{2}{*}{\multicolumn{2}{|c|}{$\begin{array}{l}\text { Users social networks } \\
\qquad \mathrm{N}=\mathbf{3 1}(62 \%)\end{array}$}} & \multirow[b]{3}{*}{ t-value } \\
\hline & & & & & \\
\hline & Mean & $\begin{array}{r}\text { Standard } \\
\text { deviation }\end{array}$ & Mean & $\begin{array}{l}\text { Standard } \\
\text { deviation }\end{array}$ & \\
\hline Concentrated feed (kg per year) & 4,089 & 351 & 4,177 & 285 & $-0.97 * *$ \\
\hline $\begin{array}{l}\text { Veterinary care (number of visits per } \\
\text { year) }\end{array}$ & 2.79 & 0.63 & 2.58 & 0.62 & 1.14 \\
\hline Working hours (h) & 321 & 216 & 281 & 169 & 0.71 \\
\hline
\end{tabular}

* Significant at the $10 \%$ level; ** Significant at the $5 \%$ level; *** Significant at the $1 \%$ level.

Non-users of SNs note difficulties in accessing the necessary amounts of concentrated feed, especially during certain suture periods. For their part, SNs users report that problems with the availability, quantity and even quality of such feeds are reduced considerably as a result of using SNs. SNs can be used to act mainly on two parameters:

- Informational monitoring: SNs allows users to have a better visibility on the state of the input market insofar as they can be informed on the evolution of supply in more or less real time. Certain elements, accessible free of charge, are more or less reliable indicators, such as the quantities put up for sale by input producers and alerts issued by livestock owners in other regions. This information enables livestock owners in the region to take preventive measures and avoid stock shortages (early searches, spatially oriented searches, stock building).

- Access to more abundant supply: The SNs have enabled users to build up highly developed networks of suppliers over time. According to the respondents, these networks generally include suppliers from the 
wilaya of Ghardaïa as well as from neighboring wilayas and sometimes even from distant wilayas. At the time of the transactions, livestock owners using SNs consult a relatively larger number of suppliers in a short time (Expression of a request on the groups and rapid contact). Even during periods of low supply, having access to many suppliers still enables the livestock owners in question to purchase the quantities they need. This means that supply from SNs rather than the conventional informational system, usually small and slow channels, greatly reduce the risk of unavailability.

\section{Conclusions}

Private alternatives to standard agricultural information systems are emerging significantly, especially in developing countries where markets are the most imperfect. The most important of these alternatives consists of collaborative systems emerging via social networks (SNs). The emergence of this new mode to access information has resulted in the rise of many debates, both academic and developmental, concerning its current place in the local production system and its capacity to fill the gap left by the conventional information system. This study contributes to this debate by evaluating the impact of SNs on the performance of dairy farmers in Ghardaia, Algeria.

The results of our study show the place occupied by the SNs, which are used by $62 \%$ of our sample, with free access, but remains conditioned by structural characteristics specific to the farmer, namely, age and level of education. The importance of SNs is reflected in their positive impact on the performance of the farms surveyed. Indeed, the difference in annual net profit per dairy cow of SNs users compared to non-users is very significant (more than $92.000 \mathrm{DZD}$ ). These variations in profit can be explained by both production costs and yields per cow.

Firstly, SNs users make significant savings on annual costs per cow amounting to 13.000 DZD; these savings are achieved through better information collected on the SN. Indeed, the descriptive and statistical analysis carried out showed that the information provided by the SNs mainly allowed farmers to reduce their labour costs. Secondly, among the determinants of milk yields, the quantity (and quality) of concentrate feed seems to be the most important one, and the SNs allow farmers to access better offers (wider choice, better quality products and better prices) especially for this feed, which has the effect of improving the yield of their farms.

It should also be noted that the social networks used by our breeders are popular social networks (such as Facebook and YouTube) and not professional, the information circulating there is not controlled a priori and is not necessarily complete. This is in contrast to institutionalised collaborative systems, where information is provided and validated by experts. In spite of this fact, this information can significantly improve the performance of farms.

It should be mentioned that other factors, independent of the SNs, also explain these significant differences in profit, notably the relatively more entrepreneurial nature of SNs users. This entrepreneurial attitude affects investment, technical itinerary, risk-taking and thus performance.

Most of the results obtained are in line with those put forward in the literature by similar works, describing (i) the nature of this information system (Facebook and YouTube - Bite and Anand, 2017; Wyn and Penri, 2017), (ii) the elements constraining its development (Difficulties in use by older and less educated farmers - Wyn and Penri, 2017) and (iii) asserting its positive effects on costs and yields, and thus on farmers' productive and economic performance (Casey et al. 2016; Wyn and Penri 2017; Bite and Anand 2017). A difference is however noted with the results of other studies, it concerns the time of consultation of SRs by our farmers (Casey et al., 2016).

The potential of SNs seems clear. They allow better supply/demand matching, faster dissemination of information and cheaper access to information. However, two main limitations of this collaborative system in Ghardaïa should be mentioned, namely (i) the difficulties in using them and (ii) the limited availability and reliability of technical information. Difficulties of use constitute a major limitation since they concern intrinsic elements of the operation, which are difficult to change. The second limitation is a direct consequence of the horizontal organization of this collaborative system, based on exchanges between actors of the same category (farmers) in the absence of an information-producing actor. To make better use of these platforms and make SNs a real information system complementary to the conventional system, these limits must be overcome. To do so, several actions are possible, such as (i) to upgrade farmers' knowledge enabling them to use of information and communication technologies, (ii) the twinning of conventional linear systems and collaborative systems in order 
Nechar \& Assassı \& Bendrissou

What Impact of Social Networks on Farmer's Performances: Case of The Milk Sector in Ghardaïa, Algeria to give a vertical dimension to the latter and/or (iii) the creation of digital platforms for collecting and disseminating information specific to state institutes to serve as an information production and verification body for the collaborative system. The implementation of these solutions requires a deepening of knowledge on the use of SNs in agriculture. The Other issues, such as the twinning models to be adopted, the farmer upgrading actions to be carried out and the organizational model to be set up, therefore deserve to be addressed in the future. 


\section{References}

Allen K., Abrams K., Meyers C., and Shultz A. (2012). A Little Birdie Told Me About Agriculture: Best Practices and Future Uses of Twitter in Agricultural Communications, Journal of Applied Communications 94 (3 \& 4): 6-21.

Anseur O. (2009). Les pratiques informationnelles des agriculteurs en Algérie : Quelle place pour le travail collaboratif ? 7th Colloquium of the French chapter of ISKO Collective intelligence and knowledge organisation. 24th-26th June. Lyon, France.

Assassi S., Daoudi A., Lejars C. (2017). Les profits « excessifs » des commerçants de fruits et légumes en Algérie : réalité ou préjugé infondé ? Le cas de la tomate primeur à Biskra. Cahiers Agricultures $26: 25002$.

Assassi S., Daoudi A., Colin JPh. (2020). Quelle place pour les petits exploitants dans l'agriculture contractuelle ? Le cas de la tomate industrielle en Algérie. Cahiers Agricultures 29:26.

Baroud K., Colin JPh., Daoudi A. (2018). La politique d'accès à la propriété privée des terres mises en valeur en zones arides en Algérie. Éléments de discussion. Économie rurale $363: 81-98$.

Bedrani S. (1993). La vulgarisation agricole au Maghreb : essai de synthèse d'un séminaire. Cahiers Options Méditerranéennes 2 (1) : 3 -11.

Bedrani S. (1994). L'état et la vulgarisation agricole. Cahiers Options Méditerranéennes ; 2(4) : 5-12.

Bite B., Anand A. (2017). A Study on Role of Social Media in Agriculture Marketing and its Scope. Global Journal of Management and Business Research: E Marketing 17 (1): 33- 36.

Casey M.J., Meikle A., Kerr G., Stevens D. (2016). Social media - a disruptive opportunity for science and extension in agriculture? Hill Country -. Grassland Research and Practice Series 16: 53-60.

Daoudi A., Colin JPh., Terranti S., Assassi S. (2017). L’agriculture contractuelle en Algérie: radiographie de dispositifs public-privé, 33rd Development Days of the Third World Association.22, 23 and 24 May. Brussels, Belgium.

Davis F., Bagozzi R., Warshaw PR. (1989). User Acceptance of Computer Technology: A Comparison of Two Theoretical Models. Management Science 35(8):982-1003.

Delice H., Yaslıglu E. (2021). The Effect of Building Orientation on Utilization of Solar Energy in Dairy Cattle Barns. Journal of Tekirdag Agricultural Faculty. September 2021, 18(3). DOI: 10.33462/jotaf.799558.

Demiryurek K., Erdem H., Ceyhan R., Vysal O. (2008). Agricultural information systems and communication networks: the case of dairy farmers in the Sansun province of Turkey. Information Research, ISSN-e 1386-1613, vol $13 \mathrm{~N}^{\circ} 2$.

Galtier F., David-Benz H., Subervie J., EGG J. (2014). Les systemes d'information sur les marchés agricoles dans les pays en developpement: nouveaux modéles, nouveaux impacts. Cahiers Agricultures. 23 (4-5) : 241-258.

Goulet F. (2011). Accompagner et vendre. Les firmes de l'agrofourniture dans l'innovation et le conseil en agriculture. Cahiers Agricultures $20: 382-386$.

Hansen J. P., Melby Jespersen L., Brunori G., Leck Jensen A., Holst K., Mathiesen C., Halberg N., Ankjær Rasmussen I. (2014). ICT and social media as drivers of multi-actor innovation in agriculture. World Conference on Computers in Agriculture and Natural Resources. July 27th-30th. San Jose, Costa Rica.

Issolah R., Anseur O., Sor J. (2010). Knowledge society and collective intelligence. Factors in capacity-strengthening in African countries. 3d International Conference on Information Systems and Economic Intelligence. February 18-20. Sousse, Tunisia.

Kizilaslan N., Agricultural information systems: a national case study. Library review. 55 (8): 497-507.

Laouar N., Dugué P. (2019). Acteurs privés dans le conseil agricole : le secteur maraîcher en Algérie. Grain de sel 77 (1) : 19-20.

Ministry of Agriculture and Rural Development (MADR), Agricultural Statistics, 2015, 2017, 2018, 2020.

Mukherjee A., Joshi P., Sharma N., Rakcha, Mahra G. (2017). Social media in agriculture: a new paradigm for extension and advisory services. Indian Farmers Digest: 4-7.

Ramezanı M., Papzan A. (2021). Investigating the Causes of Entrepreneurs Failure to Start-up Greenhouse Business in Isfahan Province, Iran. Journal of Tekirdag Agricultural Faculty May 2021, 18(2)

Ruttan V., Hayami Y. (1984). Towards a Theory of Induced Institutional Innovation. Journal of Development Studies 20 (4): $203-223$.

Vidanapthirana N. (2012). Agricultural information systems and their applications for developement of agriculture and rural community, a review study. 35th information systems research. Seminar in scandinavia-IRIS (vol.1, pp 1-14).

Wyn M., Penri J. (2017). Social Media, an Entreptreneurial Opportunity for Agricultural Based Entreprises. Journal of Small Business and Entreprise Development 24 (4): 1028-1045. 